MATEC Web of Conferences 15, 01039 (2014)

DOI: $10.1051 /$ matecconf/ 20141501039

(C) Owned by the authors, published by EDP Sciences, 2014

\title{
Performance of Polymer Modified Mortar with Different Dosage of Polymeric Modifier
}

\author{
Shankar Ganesan ${ }^{1}$, Md Azree Othuman Mydin ${ }^{2}$, Norazmawati Md. Sani ${ }^{3}$, Adi Irfan Che Ani ${ }^{4}$ \\ ${ }^{1,2,3}$ School of Housing, Building and Planning, Universiti Sains Malaysia, 11800 Penang, Malaysia \\ ${ }^{4}$ Department of Architecture, Faculty of Engineering \& Built Environment, Universiti Kebangsaan \\ Malaysia, Bangi 43600, Malaysia
}

\begin{abstract}
Polymer modified mortar system is defined as hydraulic cement combined at the time of mixing with organic polymers that are dispersed or re-dispersed in water, with or without aggregates. The compressive strength and flexural strength of polymer modified mortar obtained at early age are low and it required prolong curing period for the strength enhancement. In order to enhance the mechanical properties of cementitious mixture as well as its durability, hybridization of polymeric modifiers are applied into cementitious mixture specimens. Thus, this study is intended to examine the mechanical properties of hybrid polymer modified mortar system at various levels of polymeric modifier dosage; styrene-butadiene rubber (SBR) latex and epoxy resin. Laboratory tests for density, compressive strength and flexural strength were carried out to determine the strength of hybrid polymer modified mortar. In this study, the hybrid polymer of SBR latex with epoxy resin gives discontented results compared to unmodified cement system. The results of density, compressive strength and flexural strength of hybrid polymer modified cement system had shown negative outcomes and did not make any improvement to cement system.
\end{abstract}

\section{Introduction}

For the past few decades, multiple researches had taken place in the subject of polymer modified mortar, polymer mortar and polymer impregnated mortar. At present, these materials are largely employed as popular construction materials because of comparative high performance, multifunctionality and sustainability in comparison to conventional cement concrete. Concrete polymer mortar is environmental friendly and confirm to concerns of saving of natural resources, the permanence of infrastructures and the environmental protection [1]. Polymer modified mortar can be defined as hydraulic cement system combined at the time of mixing with organic polymers which are dispersed in water, with or without the existence of aggregates [2].

It should be pointed out that lowering the polymer to cement ratio has no major contributions of enhancing effects on strength and durability [3]. They explained that the connections between the aggregates are very thin as if only an admixture for the cementitious material [4]. At higher polymer to cement ratios, the polymer film becomes denser, has stronger bridging effects between the aggregates and forms continuous polymer film throughout the binder matrix [5]. It seems to become a secondary binder matrix to the composite material [6,7]. The polymer films would also become denser which indicates that the cement hydrates and cement particles are thoroughly mixed with the polymer 
particles and the polymer film [8,9]. The hydration of the cement is reflected in the strength development of the material $[10,11]$.

In addition, flexural strength also increases if a dry curing period is executed. The dry condition promotes a polymer film formation due to the coalescence of polymer particles [12,13]. They reported there is no improvement in flexural strength observed in the case of standard cured as long as no dry curing period is applied on the polymer modified mortar samples [14,15]. As soon as the polymer modified mortar samples exposed to dry environment for curing purpose, the film formation process would start immediately and build up through the entire binder phase [16].

\section{Experimental Program and Setup}

For this study, the mix proportion of polymer modified mortar is calculated based on Standard Mix Design according to British Department of Environment (DoE) method. Table 1 shows the mix proportion of mortar specimens fabricated for this study. Size of $50 \mathrm{~mm}$ in length, $50 \mathrm{~mm}$ in width, and $50 \mathrm{~mm}$ in height for cube specimens were prepared to determine the density at the age of 56 days, and the compressive strength at the age of 3, 7, 14, 28 and 56 days under water curing. Besides, size of $160 \mathrm{~mm}$ in length, $40 \mathrm{~mm}$ in width, and $40 \mathrm{~mm}$ in height for prism specimens were prepared to determine flexural strength at 3, 7,14 28 and 56 days under water curing. In addition, size of $500 \mathrm{~mm}$ in length, $100 \mathrm{~mm}$ in width, and $100 \mathrm{~mm}$ in height for prism specimens were prepared to determine water absorption and air permeability at the age of 28 and 56 days [17]. After the specimens are being cured for certain period, there are few laboratory tests to be carried out to determine the engineering properties and durability properties of polymer modified mortar specimens.

Table 1: Mix proportion of mortar specimens

\begin{tabular}{|c|c|c|c|c|c|}
\hline Mortar mix & $\begin{array}{c}\text { Cement } \\
\left(\mathrm{kg} / \mathrm{m}^{3}\right)\end{array}$ & $\begin{array}{c}\text { SBR latex } \\
(\%)\end{array}$ & $\begin{array}{c}\text { Epoxy resin } \\
(\%)\end{array}$ & $\begin{array}{c}\text { Fine aggregates } \\
\left(\mathrm{kg} / \mathrm{m}^{3}\right)\end{array}$ & w/c ratio \\
\hline $\mathrm{C}$ & 410 & - & - & 1730 & 0.5 \\
\hline $\mathrm{H} 5$ & 410 & 5 & 5 & 1730 & 0.5 \\
\hline $\mathrm{L}$ & 410 & 10 & 5 & 1730 & 0.5 \\
\hline $\mathrm{E}$ & 410 & 5 & 10 & 1730 & 0.5 \\
\hline $\mathrm{H} 10$ & 410 & 10 & 10 & 1730 & 0.5 \\
\hline
\end{tabular}

\subsection{Density of Hardened Specimen}

This test is carried out when the polymer modified mortar specimens were cured for certain ages and according to BSI 12390-7 (2009). The weight of each sample in both air and water condition are recorded by using weighing machine. The mass and volume of the specimen of hardened mortar are determined and the density calculated.

\subsection{Water absorption}

For durability properties investigation, water absorption test method is specified in BS 1881-122. A $75 \mathrm{~mm}$ in diameter and $100 \mathrm{~mm}$ in height coring cylinder sample with 24-hours oven-dried is weighted first and soaked in water for 30 minutes [18]. After that, the cylinder sample was taken out and the weight in both air and water condition were recorded.

\subsection{Compressive Strength}

The compressive strength test for mortar specimens has been conducted using compressive test machine. To obtain the maximum compressive load, an increasing compressive load was applied to the specimen until the failure occurred. Sample used for compression test are size in $50 \mathrm{~mm}$ length, 50 $\mathrm{mm}$ width, and $50 \mathrm{~mm}$ height cube [18]. 


\subsection{Flexural Strength}

Flexural strength test gave two important parameters which its first crack strength controlled by the matrix and the ultimate flexural strength or the modulus of rapture is determined by the maximum load. The maximum reading showed at the display before the specimen failed is recorded. Sample used for flexural strength test are $160 \mathrm{~mm}$ length, $40 \mathrm{~mm}$ width, and $40 \mathrm{~mm}$ height prisms [17].

\section{Results and Discussions}

\subsection{Density of Hardened Mortar Test}

The results obtained for density of specimen are shown in Table 2. It is obvious that control mortar obtained the highest density among the mortar specimens which is $2290 \mathrm{~kg} / \mathrm{m}^{3}$ at the age of 56 days. At the same age, hybrid polymer modified mortar L obtained the lowest density which is 2140 $\mathrm{kg} / \mathrm{m}^{3}$ compared to other mortar specimens. This is due to the high content of SBR latex in hybrid polymer modified mortar L. SBR latex contained low solid content and increased the water to cement ratio of hybrid polymer modified mortar L. Hence, the great reduction of density in hybrid polymer modified mortar L occurred after water cured process.

Table 2: Density of hardened mortars $\left(\mathrm{kg} / \mathrm{m}^{3}\right)$

\begin{tabular}{|c|c|}
\hline Mortar Mix & Age (day) 56 \\
\hline C & 2290 \\
\hline H5 & 2200 \\
\hline L & 2140 \\
\hline E & 2190 \\
\hline H10 & 2210 \\
\hline
\end{tabular}

On the other hand, the density of H5, E, and H10 are relatively same within the range of 2190 to $2210 \mathrm{~kg} / \mathrm{m}^{3}$ in time length of 56 days. It can be concluded that higher epoxy resin content in hybrid polymer modified mortar specimens did not give any significant contribution in reduction or increment of mortar density.

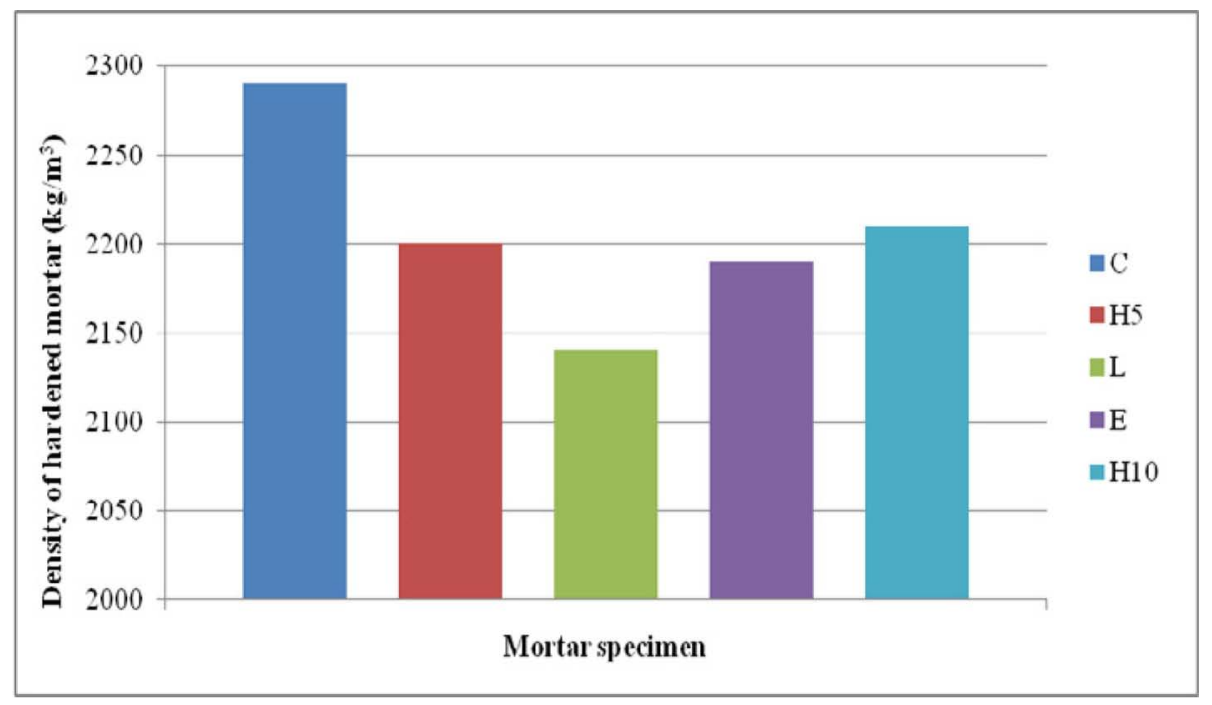

Figure 1: Density of hardened mortar at 56-day 
From Fig. 1, it can be seen that hybrid polymer modified mortars is of lower density compare to unmodified mortar due to the polymeric admixtures in mortar mix. This is because the hybrid polymer admixture contained low solid content and it led to deduction in density of modified mortar specimens.

Table 3: Reduction in density of hardened mortar

\begin{tabular}{|c|c|}
\hline Mortar mixes & Percentage of reduction (\%) \\
\hline H5 to C & 3.9 \\
\hline L to C & 6.6 \\
\hline E to C & 4.4 \\
\hline H10 to C & 3.5 \\
\hline
\end{tabular}

The percentage of density reduction of hybrid polymer modified mortars compared to unmodified mortar is presented in Table 3. At the age of 56 days, the density of hybrid polymer modified mortar L was found to be lower than the density of control mortar by $6.6 \%$ which is the greatest reduction in density. Followed by hybrid polymer modified mortar E, the reduction of density found by $4.4 \%$ compared to control mortar. The density reduction of hybrid polymer modified mortars $\mathrm{H} 5$ and $\mathrm{H} 10$ are relatively of the same range, which is by $3.9 \%$ and $3.5 \%$ respectively.

\subsection{Water Absorption Test}

In this study, water absorption test according BS 1881: 122 is used to determine the durability properties of mortar specimens. This parameter is important as it relates with gas absorption, chloride penetration, porosity which contributes to durability properties of mortar. The results at the age of 28 and 56 days are shown in Table 4.

Table 4: Percentage of water absorption for mortar specimens

\begin{tabular}{ccccccc}
\hline \multirow{2}{*}{ Mortar Mix } & & 28 days & & & 56 days \\
& Dry $(\mathrm{g})$ & Wet $(\mathrm{g})$ & $\%$ & Dry $(\mathrm{g})$ & Wet $(\mathrm{g})$ & $\%$ \\
\hline C & 748.3 & 776.5 & 3.8 & 777.7 & 794.6 & 2.2 \\
H5 & 715.4 & 728.7 & 1.9 & 751.5 & 765.1 & 1.8 \\
L & 673.5 & 696.6 & 3.4 & 711.2 & 735.5 & 3.4 \\
E & 697.2 & 713.0 & 2.3 & 738.9 & 754.6 & 2.1 \\
H10 & 718.3 & 729.6 & 1.6 & 761.4 & 773.0 & 1.5 \\
\hline
\end{tabular}

As can be seen in Table 4 and Fig. 2, hybrid polymer modified mortar doing better water penetration resistance at age of 28 and 56 days. H10 achieved the lowest percentage of water absorption which is only $1.5 \%$ and it showed the enhancement of durability for cement system. Control mortar shown reduction in the percentage of water absorption from $3.8 \%$ at 28 days to $2.2 \%$ at 56 days test while hybrid polymer modified mortars were maintained the percentage of water absorption. As conclusion, hybrid polymer modified mortar can optimize the water penetration resistance within 28 days and unmodified mortar need longer time to achieve.

At the age of 28 days, it can be seen that the significant improvement in water tightness by hybrid polymer modified mortars. H10 obtained the greatest reduction in water absorption by $57.9 \%$ compared to control mortar and followed by H5 (50.0\%), E (39.5\%), and L (10.5\%). The advantage is water tightness by hybrid polymer modified mortars has remained at the age of 56 days except for hybrid polymer modified mortar L. While all specimens have obtained improvements in reduction of water absorption, hybrid polymer modified mortar L remained in same condition and found to exceed by $54.5 \%$ compared to control mortar at 56 days. 


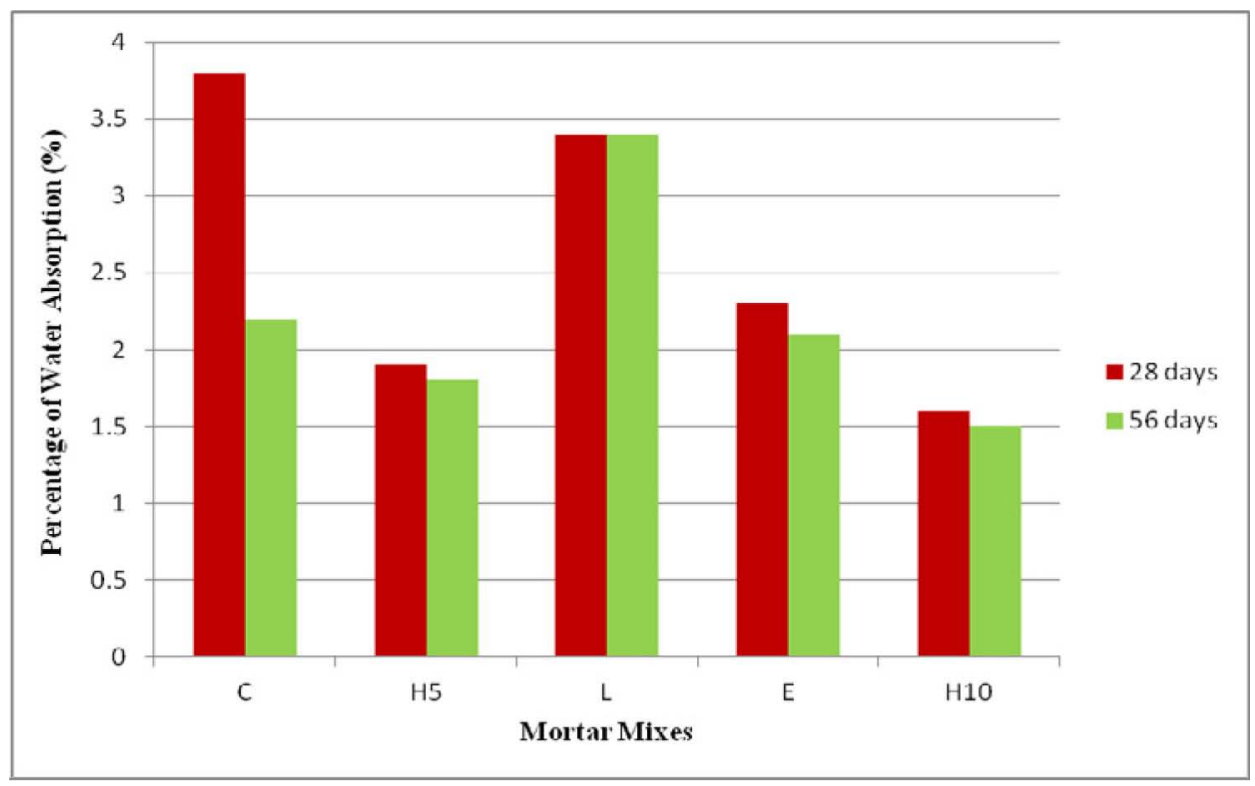

Figure 2: Percentage of water absorption by mortar mixes

\subsection{Compressive Strength Test}

The most important properties in cement system are strength as it gives an overall picture of the quality of cement based material system. Among the various strength of mortar or concrete system, the most concerned is compressive strength. The results of compressive strength test of mortar cubes with respective hybrid polymer dosage at the age of $3,7,14,28$ and 56 days are shown in Table 5. Figure 5 shows the compressive strength - age relation for mortar specimens.

Table 5: Compressive strength of unmodified mortar and polymer modified mortar cubes $\left(\mathrm{N} / \mathrm{mm}^{2}\right)$

\begin{tabular}{|c|c|c|c|c|c|c|}
\hline \multirow{2}{*}{ Mortar Mix } & \multicolumn{7}{|c|}{ Age (day) } \\
\cline { 2 - 8 } & 3 & 7 & 14 & 28 & 56 & \\
\cline { 2 - 8 } & 30.8 & 37.5 & 38.4 & 40.7 & 42.4 & \\
\hline C & 8.2 & 11.8 & 14.0 & 17.7 & 18.8 & \\
\hline H5 & 6.9 & 9.9 & 12.6 & 16.6 & 18.2 & \\
\hline L & 10.9 & 14.9 & 16.8 & 21.7 & 23.2 & \\
\hline E & 8.5 & 11.7 & 13.4 & 17.5 & 18.7 & \\
\hline H10 & & & & & \\
\hline
\end{tabular}

In this study, hybrid polymer modified mortars achieve lower compressive strength compared to unmodified mortar from the age of 3 days to 56 days. Table 8 presented that control mortar obtained the highest reading among mortar specimens in compressive strength test which is $42.4 \mathrm{~N} / \mathrm{mm}^{2}$ at the age of 56 days while hybrid polymer modified mortar L obtained the lowest reading which is 18.2 $\mathrm{N} / \mathrm{mm}^{2}$ at the same age. Hybrid polymer modified mortars H5 and H10 achieved relatively same compressive strength which is $18.8 \mathrm{~N} / \mathrm{mm}^{2}$ and $18.7 \mathrm{~N} / \mathrm{mm}^{2}$ in 56 days. On the other hand, hybrid polymer modified mortar E obtained the highest reading in compressive strength among hybrid polymer modified mortars which is $23.2 \mathrm{~N} / \mathrm{mm}^{2}$ in the same period of time. 


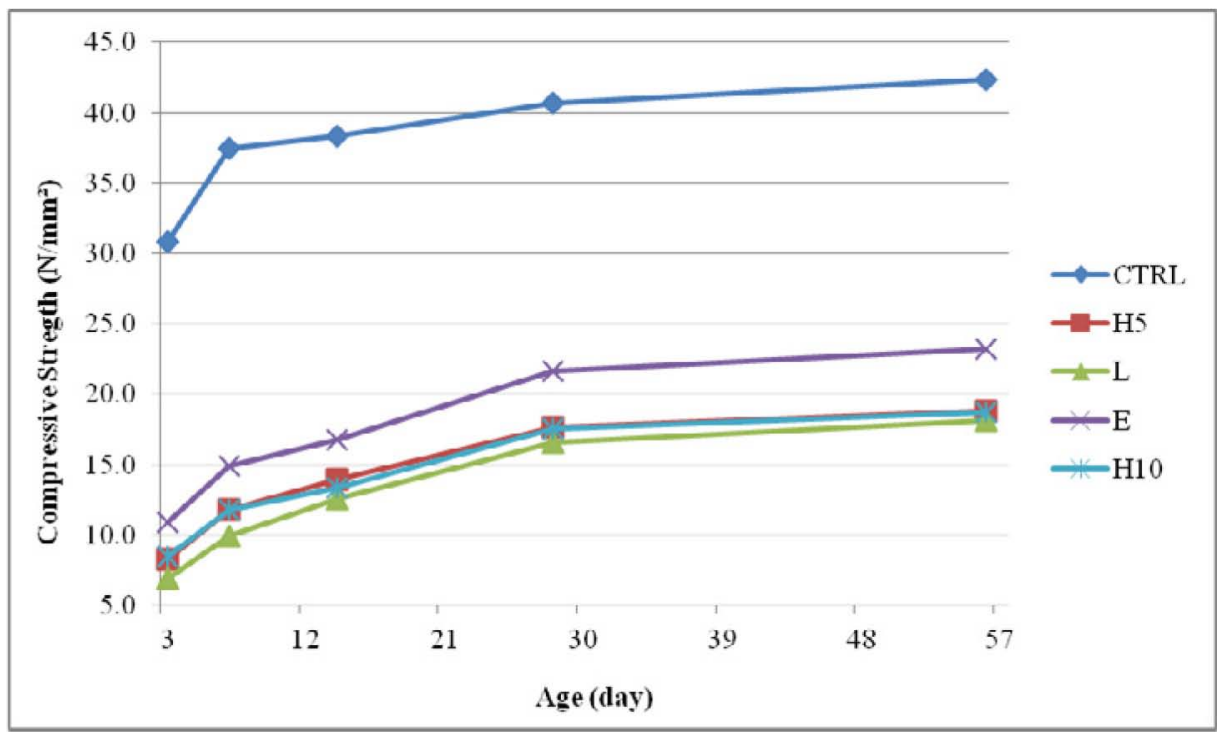

Figure 3: Compressive strength - age relation for mortar specimens

In Fig. 3, it can be seen that hybrid polymer modified mortar E had higher compressive strength and hybrid polymer modified mortar L resulted in lower compressive strength among modified mortars. Table 6 shows the percentage of reduction in compressive strength between hybrid polymer modified mortars to control mortar.

Table 6: Reduction in compressive strength

\begin{tabular}{cccccc}
\hline \multirow{2}{*}{ Mortar mixes } & \multicolumn{5}{c}{ Percentage of reduction (\%) } \\
& 3-day & 7-day & 14-day & 28-day & 56-day \\
\hline H5 to C & 73.4 & 68.5 & 63.5 & 56.5 & 55.7 \\
L to C & 77.6 & 73.6 & 67.1 & 59.2 & 57.1 \\
E to C & 64.6 & 60.3 & 56.3 & 46.7 & 45.3 \\
H10 to C & 72.4 & 68.8 & 65.1 & 57.0 & 55.9 \\
\hline
\end{tabular}

The reasons behind these outcomes are greater water to cement ratio, no air curing process included, no antifoam agent is used, and incompatible of hybrid polymer system. Hybrid polymer modifier is applied as additive but not as replacement to cement and it increased the water to cement ratio of mortar mixes. As a result, the greater water to cement ratio of mortar mixes lead to lower compressive strength for hybrid polymer modified mortar.

\subsection{Flexural Strength Test}

Mortar specimens were tested for flexural strength by applying increasing load until failure occurred. Thus, reading of the maximum load for failure can be obtained. In this study, center-point load method is used. The results of flexural strength test of mortar specimens are shown in Table 10 and Fig. 4 shows the flexural strength - age relation for mortar specimens. From Table 7, unmodified mortar achieved the highest strength in flexural test with $7.7 \mathrm{~N} / \mathrm{mm}^{2}$ at 56 days and hybrid polymer modified mortar L obtained the lowest reading in flexural strength test which is $4.5 \mathrm{~N} / \mathrm{mm}^{2}$ at day 56 . 


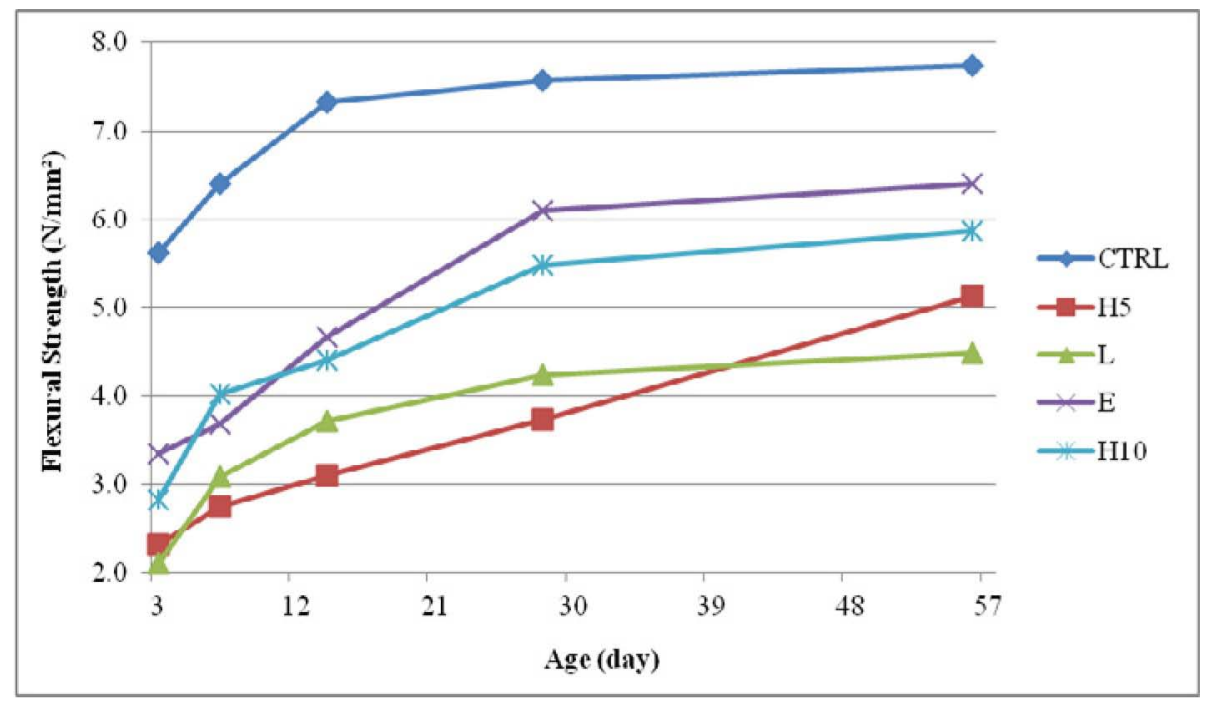

Figure 4: Flexural strength - age relation for mortar specimens

Table 7: Flexural strength of unmodified mortar and polymer modified mortar prisms $\left(\mathrm{N} / \mathrm{mm}^{2}\right)$

\begin{tabular}{|c|c|c|c|c|c|}
\hline \multirow{2}{*}{ Mortar mixes } & \multicolumn{5}{|c|}{ Percentage of reduction (\%) } \\
\cline { 2 - 6 } & 3-day & 7-day & 14-day & 28-day & 56-day \\
\hline C & 5.6 & 6.4 & 7.3 & 7.6 & 7.7 \\
\hline H5 & 2.3 & 2.7 & 3.1 & 3.7 & 5.1 \\
\hline L & 2.1 & 3.1 & 3.7 & 4.3 & 4.5 \\
\hline E & 3.4 & 3.7 & 4.7 & 6.1 & 6.4 \\
\hline
\end{tabular}

From Fig. 4, it can be seen that hybrid polymer modified mortar achieves lower flexural strength compared to unmodified mortar. This is similar to the result of compressive strength test. The major factors contributing to this result are insufficient air curing process, greater water to cement ratio, foaming process, and incompatible of hybrid polymer system.

Table 8: Reduction in flexural strength

\begin{tabular}{|c|c|c|c|c|c|}
\hline \multirow{2}{*}{ Mortar mixes } & \multicolumn{5}{|c|}{ Percentage of reduction (\%) } \\
\cline { 2 - 6 } & 3-day & 7-day & 14-day & 28-day & 56-day \\
\hline H5 to C & 58.9 & 57.8 & 57.5 & 51.3 & 33.8 \\
\hline L to C & 62.5 & 51.6 & 49.3 & 43.4 & 41.6 \\
\hline E to C & 39.3 & 42.2 & 35.6 & 19.7 & 16.9 \\
\hline H10 to C & 50.0 & 37.5 & 39.7 & 27.6 & 23.4 \\
\hline
\end{tabular}

From Table 8 , it can be seen that there was a trend of minimization in reduction of flexural strength between hybrid polymer modified mortars to control mortar. At the age of 56 days, E obtained the minimum reduction in flexural strength by $16.9 \%$ compared to $\mathrm{C}$ while $\mathrm{L}$ achieved the maximum reduction by $41.6 \%$.

\section{Conclusions}

This study had described all the processes from primary stages of mortar mix design up to the analysis of data obtained. Experimental laboratory works were carried out to obtain the data for strength and durability analysis. As conclusion, hybridization of SBR latex and epoxy resin was 
observed not a suitable material for polymer modified cement system. Based on the data gathered and analysis done, this hybrid polymer system had only shown an improvement in water absorption for durability properties. The results of density, compressive strength and flexural strength of hybrid polymer modified cement system shown vice versa outcomes and did not make any enhancement or improvement to cement system. As a result, hybridization of polymer modified cement system in this study had shown the enhancement in water tightness while conventional cement system proves better engineering properties performance and lower gas penetration compared to hybrid polymer modified cement system.

\section{Acknowledgement}

The authors would like to thank Universiti Sains Malaysia for their support under USM Short Term Grant (203/PPBGN/6312147).

\section{References}

1. Golestaneh, M., G. Amini, G.D. Najafpour, M.A. Beygi, 2010. Evaluation of Mechanical Strength of Epoxy Polymer Concrete with Silica Powder as Filler, World Applied Sciences Journal, 9 (2): 216-220

2. Pitaloka, A.B., H.S. Asep, M. Nasikin, 2013. Water Hyacinth for Superabsorbent Polymer Material, World Applied Sciences Journal, 22 (5): 747-754

3. Gorninski, J.P., D.C. Dal Molin and C.S. Kazmierczak, 2007. Strength degradation of polymer concrete in acidic environments, Cement and Concrete Composites, 29 (8): 637-645

4. Muthukumar, M. and D. Mohan, 2005. Studies on Furan Polymer Concrete, J. Polymer Res., 12: 231-241

5. Ribeiro, M.C.S., P.R. Nóvoa, A.J.M. Ferreira and A.T. Marques, 2004. Flexural performance of polyester and epoxy polymer mortars under severe thermal conditions, Cement and Concrete Composites 26 (7): 803-809.

6. Ohama, Y., 1998. Polymer-based admixtures, Cement and Concrete Composites, 20 (2-3): 189212.

7. Mebarkia, S. and C. Vipulanandan, 1995. Mechanical properties and water diffusion in polyester polymer concrete, J. Engineering Mechanics, 121 (12): 1359-1365.

8. Vipulanandan, C. and E. Paul, 1993. Characterization of polyester polymer and polymer concrete, J. Materials in Civil Engineering, 5 (1): 62-82.

9. Vipulanandan, C. and N. Dharmarajan, 1987. Flexural behavior of polyester polymer concrete, Cement and Concrete Res., 17 (2): 219-230.

10. Czarnecki, L., A. Garbacz and J. Kurach, On the characterization of polymer concrete fracture surface, Cement and Concrete Composites, 23 (4-5): 399-409

11. Othuman Mydin, M.A., 2013. Modeling of Transient Heat Transfer in Foamed Concrete Slab. Journal of Engineering Science and Technology, 8 (3): 331-349

12. Othuman Mydin, M.A., Y.C. Wang, 2012. Mechanical properties of foamed concrete exposed to high temperatures. Journal of Construction and Building Materials, 26 (1): 638-654

13. Othuman Mydin, M.A., Y.C. Wang, 2011. Elevated-Temperature Thermal Properties of Lightweight Foamed Concrete. Journal of Construction \& Building Materials, 25 (2): 705-716

14. Othuman Mydin, M.A., 2011. Thin-walled steel enclosed lightweight foamed concrete: A novel approach to fabricate sandwich composite. Australian Journal of Basic and Applied Sciences, 5 (12): 1727-1733

15. Norgaard, J., M.A. Othuman Mydin, 2013. Drywall Thermal Properties Exposed to High Temperatures and Fire Condition. Jurnal Teknologi, 62 (1): 63-68 
16. Othuman Mydin, M.A., 2013. An Experimental Investigation on Thermal Conductivity of Lightweight Foamed concrete for Thermal Insulation. Jurnal Teknologi, 63 (1): 43-49

17. Othuman Mydin, M.A., Y.C. Wang, 2011. Structural Performance of Lightweight Steel-Foamed Concrete-Steel Composite Walling System under Compression. Journal of Thin-walled Structures, 49 (1): 66-76

18. Soleimanzadeh, S., M.A. Othuman Mydin, 2013. Influence of High Temperatures on Flexural Strength of Foamed Concrete Containing Fly Ash and Polypropylene Fiber, International Journal of Engineering, 26 (1): 365-374 